\title{
Análise das feições de dissecação do relevo na folha topográfica de São Pedro do Sul - RS
}

\author{
JaIR ANTÔNIO RAFFAELLI \\ Mauro Kumpfer WerLang
}

\section{RESUMO}

A pesquisa teve como objetivo observar, localizar, analisar e mapear as diferentes categorias de relevo, sua área e distribuição espacial, em função dos índices de dissecação do relevo na folha topográfica de São Pedro do Sul-RS, utilizando-se a metodologia formulada inicialmente pelo Projeto RADAMBRASIL (1986) e posteriormente adaptada por ROSS (1992 e 1996), para o estudo da dissecação do relevo. A metodologia foi adaptada para a escala de levantamento $(1: 50.000)$ e mostrou-se eficiente para estudos dessa natureza. Leva em consideração basicamente a dimensão interfluvial e o grau de entalhamento dos canais fluviais. A área em estudo apresenta-se sobre duas porções distintas: a Depressão Central do Rio Grande do Sul e o Rebordo do Planalto Meridional Brasileiro, predominando na primeira, áreas com relevo plano e suave ondulado e na segunda áreas com declives forte ondulados e escarpados. As áreas observadas com menor grau de dissecação encontram-se predominantemente na área da Depressão Central, enquanto os setores que apresentam um maior grau de dissecação estão na região do Rebordo do Planalto. Os resultados obtidos mostram que a área apresenta-se predominantemente com índices de dissecação fraca e média. 


\section{ABSTRACT}

The investigation purpose was to observe, to localize, to analyse and to catalogue the different kinds of relieve, with its area and spacial distribution, based on the relieve dissection indexes of the São Pedro do Sul-RS topographic map, using the metodology first formulated by RADAMBRASIL PROJECT (1986) and after adapted by ROSS (1992 and 1996), to the relieve dissection study. The metodology was adapted to the survey scale (1:50000) and was shawed as efficient to these types of studies. It basically consider the interfluvial dimension and the fluvial channels carving degree. The study area is located on two distincts parts: the Central Depression of the Rio Grande do Sul and the edge Rio Grande do Sul Central Depression and the Brazilian Meridional Tableland edge. The first part has mainly areas with a plane os smooth wavy and the second part with strong slope and rugged. The areas observed with less dissection degree are situated mainly at the Central Depression part, whereas the sectors that shows a bitter dissection degree are located at the tableland edge. The results obtained shows that the area has predominantly medium to weak dissection indexes.

\section{INTRODUÇÃo}

Nas últimas décadas tem-se observado um grande crescimento populacional, e com isso a forma de uso da terra vem sofrendo transformações, tendo como conseqüência alterações na dinâmica da paisagem, promovidas pela concentração populacional e pelo processo de industrialização.

Alia-se ao aumento dos aglomerados urbanos e industriais, a substituição da cobertura florestal original pelos mais diversos tipos de usos, como a crescente utilização da terra com agricultura e pecuária, construção de barragens e estradas, motivando alterações no comportamento dos parâmetros ambientais.

Com o desenvolvimento e implementação das técnicas de mecanização na agricultura brasileira nos últimos anos, um empobrecimento e desgaste do solo através dos processos erosivos tem sido sentido. Assim, passa existir uma necessidade maior de estudos topográficos que buscam conhecer as diferenças altimétricas, que podem ser explicadas pela morfologia do terreno. Conforme CASSETI (1994), a geomorfologia é a ciência que tem por objetivo analisar as formas do relevo, buscando entender as relações pretéritas e atuais. Em relação às formas de ocupação do espaço, defende 
o autor, que a geomorfologia constitui um importante subsídio para a compreensão racional da forma de apropriação do relevo pelo homem. Afirma ainda ser possível definir, através da geomorfologia, diferentes graus de risco que uma área apresenta para o desenvolvimento da vida.

Nesse sentido VIEIRA (1993), comenta que o meio físico é um complexo resultante da interação de um conjunto de fatores naturais, de cuja compreensão e conhecimento necessita-se para manejá-lo de tal maneira que seja possivel conservar ou aumentar a sua potencialidade produtiva.

O trabalho teve como objetivos a análise das fácies de dissecação do relevo da carta topográfica de São Pedro do Sul, aplicando-se a metodologia proposta pelo Projeto RADAMBRASIL e ROSS (1992; 1996), buscando verificar a sua aplicabilidade em estudos locais. Teve ainda como objetivos específicos: a) elaborar o mapa da dissecação do relevo na escala 1:50 000 para a folha topográfica de São Pedro do Sul/RS, com base na metodologia adaptada do RADAMBRASIL (1986) e ROSS (1992; 1996); b) quantificar, descrever e analisar as fácies de dissecação da folha topográfica de São Pedro do Sul por categoria de dissecação mapeada; c) apresentar o mapa de dissecação do relevo obtido em meio digital na escala 1:50 000, utilizando-se do Software Siter 1.0.

\section{MATERIAIS E MÉTODOS}

\subsection{Localização e caracterização geral da área}

A área em estudo refere-se a folha topográfica de São Pedro do Sul- Folha SH-21-X-D-VI-2, que abrange parte dos municipios de São Pedro do Sul e Dilermando de Aguiar. A folha topográfica da DSG, de São Pedro do Sul, na escala de 1:50.000, está limitada pelos paralelos de $29^{\circ} 30^{\prime}$ a $29^{\circ} 45^{\prime}$ e pelos meridianos de $54^{\circ} 00^{\prime}$ a $54^{\circ} 15^{\prime} \mathrm{W}$, localizando-se na parte central do Estado do Rio Grande do Sul.

Situada sobre uma zona de transição entre o Planalto Meridional Brasileiro e a Depressão Central do Rio Grande do Sul, apresenta paisagens características desses dois compartimentos geomorfológicos. A porção Norte da área, individualiza-se por apresentar o compartimento denominado de Rebordo do Planalto, com feições morfológicas escarpadas, morros residuais, e depósitos de talude. Na porção Sul, encontram-se áreas sedimentares com amplas planícies aluviais, configurando relevo plano e suave ondulado 
das colinas (coxilhas).

A região tem sua economia baseada no setor primário, destacando-se os cultivos de soja, milho, fumo, feijão, arroz e a criação de bovinos de corte. Entre essas atividades a cultura do arroz e a criação de gado representam a maior fonte de renda das propriedades.

\subsection{Materiais}

Para a elaboração da carta de dissecação do relevo foram utilizados materiais, instrumentos de laboratório além de software. Os materiais utilizados foram: Carta Topográfica, Aerofotogramas, Imagens TM do Satélite Landsat 5, estereoscópio de bolso; estereoscópio de espelho com barra de paralaxe, papel vegetal, máquina calculadora, lapiseira $0,5 \mathrm{~mm}$; lápis de cor; grafite preto e colorido de $0,5 \mathrm{~mm}$; prancheta de campo, hardware (IBM 686) com $100 \mathrm{MHz}, 16$ Mbytes de memória RAM, drive de 31/2 e software (Idrisi for Windows, versão 2.0 , Siter 1.0, Adobe Photoshop, versão 4.0, Word for Windows 97), que serviram para auxiliar nos trabalhos de elaboração do mapa de dissecação do relevo.

\subsection{Métodos}

\subsubsection{Elaboração do Mapa Base}

Obteve-se o mapa base a partir da folha topográfica de São Pedro do Sul (da Diretoria do Serviço Geográfico-DSG, na escala 1:50 000), tomando como material de apoio fotografias aéreas na escala aproximada de 1:60 000 do levantamento aerofotogramétrico realizado em 1964 pelo AST-10 e também fotografias na escala aproximada de 1:110 000 do levantamento realizado em 1975, pelo SACS. (Serviço Aerofotogrametrico Cruzeiro do Sul).

Também nesta etapa, utilizou-se imagens de setembro de 1999 do sensor TM LANDSAT-5, onde através da interpretação visual sobre a composição colorida $3 / 4 / 5$, detalhou-se a rede de drenagem, buscando-se um maior grau de detalhamento aos índices de dissecação do relevo.

De posse das informações referentes a base cartográfica, com o auxilio da mesa digitalizadora criou-se a base cartográfica em formato digital. Para isto foi usado o Sistema de Informações Geográficas SITER 1.0. Com base nos dados da dimensão interfluvial e do entalhamento fluvial enquadrando-se nas categorias morfométricas obteve-se a carta de dissecação do relevo. 
Para a obtenção dos dados e a elaboração da carta de dissecação do relevo, tomou-se como referência a Matriz dos índices de dissecação adaptada de ROSS (1992 e 1996), que está baseada em informações da dimensão interfluvial média, nas colunas horizontais e entalhamento médio dos vales nas colunas verticais. Assim a dimensão interfluvial ficou classificada em: Muito grande, Grande, Média, Pequena e Muito pequena e o entalhamento médio dos vales ou classes de entalhamento classificam-se em: Muito fraca, Fraca, Média, Grande e Muito grande, conforme mostra o quadro 1.

ROSS (1996), observa que, para o mapeamento em escalas médias e pequenas (1:250.000 e 1:100.000), devido ser difícil estabelecer classes de densidade de drenagem, opta-se por usar a dimensão interfluvial média, onde os valores são inversamente proporcionais, ou seja, quanto maior a densidade de drenagem, menor a dimensão interfluvial média.

Quad. 1. Classificação das categorias morfométricas empregadas conforme a matriz dos índices de dissecação do relevo.

\begin{tabular}{|c|c|c|c|c|c|}
\hline $\begin{array}{c}\text { Dimensão } \\
\text { Interfluvial Média } \\
\text { (Classes) }\end{array}$ & $\begin{array}{l}\text { Muito } \\
\text { Grande } \\
\text { (1) }\end{array}$ & $\begin{array}{c}\text { Grande } \\
\text { (2) } \\
750 \mathrm{a}\end{array}$ & $\begin{array}{c}\text { Média } \\
\text { (3) } \\
350 \mathrm{a}\end{array}$ & $\begin{array}{c}\text { Pequena } \\
\text { (4) } \\
150 \text { a } 50 \mathrm{~m}\end{array}$ & $\begin{array}{c}\text { Muito } \\
\text { Pequena } \\
\text { (5) }\end{array}$ \\
\hline $\begin{array}{l}\text { Entalhamento } \\
\text { Médio dos Vales } \\
\text { (classes) }\end{array}$ & $\begin{array}{l}>750 \mathrm{~m} \\
>15 \mathrm{~mm}\end{array}$ & $\begin{array}{c}350 \mathrm{~m} \\
7 \text { a } 15 \mathrm{~mm}\end{array}$ & $\begin{array}{c}150 \mathrm{~m} \\
3 \text { a } 7 \mathrm{~mm}\end{array}$ & 1 a $3 \mathrm{~mm}$ & $\begin{array}{l}<50 \mathrm{~m} \\
11 \mathrm{~mm}\end{array}$ \\
\hline $\begin{array}{l}\text { Muito fraca (1) } \\
\qquad(<\text { de } 20 \mathrm{~m})\end{array}$ & 11 & 12 & 13 & 14 & 15 \\
\hline $\begin{array}{l}\text { Fraco (2) } \\
(20 \text { a } 40 \mathrm{~m})\end{array}$ & 21 & 22 & 23 & 24 & 25 \\
\hline $\begin{array}{l}\text { Médio (3) } \\
(40 \text { a } 80 \mathrm{~m})\end{array}$ & 31 & 32 & 33 & 34 & 35 \\
\hline $\begin{array}{c}\text { Forte }(4) \\
(80 \text { a } 160 \mathrm{~m})\end{array}$ & 41 & 42 & 43 & 44 & 45 \\
\hline $\begin{array}{l}\text { Muito Forte (5) } \\
\qquad(>160)\end{array}$ & 51 & 52 & 53 & 54 & 55 \\
\hline
\end{tabular}

Fonte: Adaptado de ROSS, J. L. 1996. 


\section{RESULTADOS E DISCUSSÃO}

\subsection{Categorias de dissecação do relevo obtidos para a folha topográfica de São Pedro do Sul - RS}

Para a elaboração da carta de dissecação do relevo da folha topográfica de São Pedro do Sul, foram considerados como planos de informação, as curvas de nivel e a rede de drenagem. As curvas de nível serviram para fornecer o grau de entalhamento dos canais de drenagem para a dissecação no plano vertical, e a rede de drenagem a dimensão interfluvial média para a dissecação horizontal.

Foram encontradas predominantemente áreas com dissecação fraca. Em seguida a classe de dissecação média, forte e muito forte, respectivamente, conforme mostra ao quadro 2. Também aparecem as áreas de acumulação com grande grau de importância e com menor grau, as áreas de aplanamento. As áreas com modelado de acumulação que ocorrem na área referem-se a acumulação colúvio-aluvionares, localmente caracterizados por sedimentos arenoargilosos e, as áreas de aplanamento estão caracterizadas por superfícies inumadas. A distribuição dos modelados mapeados constam na Figura 7.

Quad. 2. Área das classes de dissecação por tipo de modelado na folha topográfica de São Pedro do Sul-RS

\begin{tabular}{|c|c|c|c|c|}
\hline \multirow{9}{*}{$\begin{array}{l}\text { M } \\
0 \\
d \\
e \\
\text { I } \\
\text { a } \\
d \\
0 \\
s\end{array}$} & \multirow{6}{*}{ Dissecação } & $\begin{array}{l}\text { Classes de } \\
\text { dissecação }\end{array}$ & $\begin{array}{l}\text { Área em } \\
\text { (ha) }\end{array}$ & $\begin{array}{l}\text { \% do total } \\
\text { da área }\end{array}$ \\
\hline & & Muito fraca & 1250 & 1,85 \\
\hline & & Fraca & 21800 & 32,40 \\
\hline & & Média & 18000 & 26,75 \\
\hline & & Forte & 11800 & 17,53 \\
\hline & & Muito Forte & 6300 & 9,36 \\
\hline & Acumulação & Acumulação & 7580 & 11,26 \\
\hline & & Aplanamento & 563 & 0,85 \\
\hline & 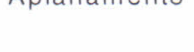 & Total & 67293 & 100,00 \\
\hline
\end{tabular}

Organização dos autores 
A classe Dissecação Muito Fraca, se faz presente em 1.250 ha, o que representa $1,85 \%$ do total da área, localiza-se em apenas uma mancha na porção Sul da carta. Está situada no intervalo de declividade entre 2 a $5 \%$, e apresenta uma baixa densidade de drenagem. As áreas pertencentes a categoria de dissecação muito fraca. Apresentam-se com modelado convexo-côncavo, caracterizando feições do domínio geomorfológico da Depressão Central. A figura 1 ilustra a classe em questão.

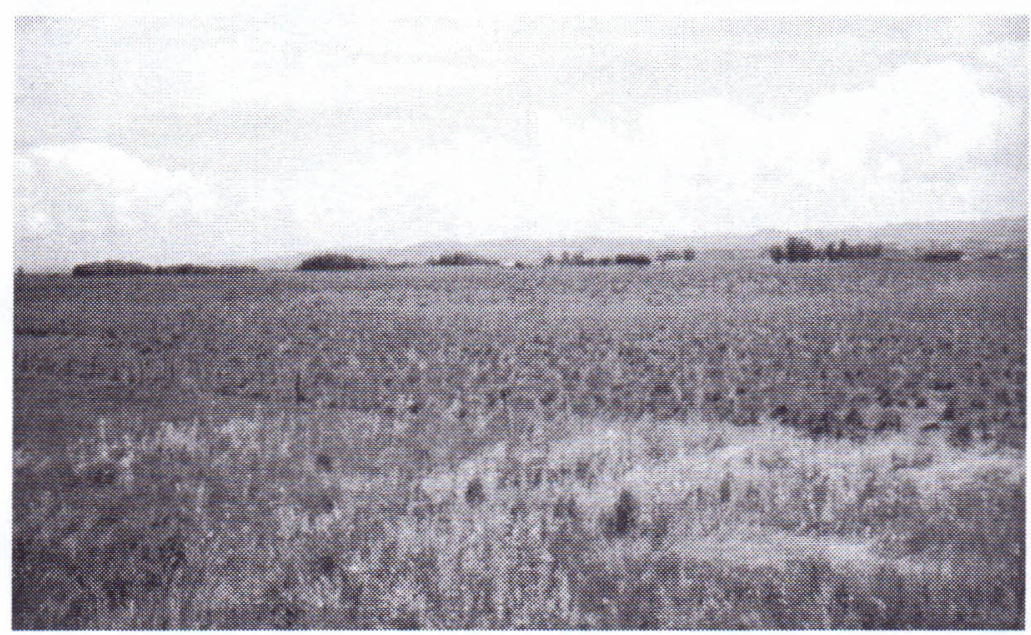

Fig. 1. Aspecto da área da categoria de Dissecação Muito Fraca do relevo. Localidade de Parada Link, município de São Pedro do Sul -RS

Fonte: Pesquisa de campo- Fevereiro - 2000

A classe de Dissecação Fraca, que é a predominante na área, ocupa aproximadamente 21.800 ha, correspondendo a $32,40 \%$ do total da área, ocupando áreas com declividades entre $5 \mathrm{a}$ $20 \%$.

As áreas pertencentes a esta classe de dissecação caracterizam-se por apresentar um relevo ondulado na forma de modelado convexo-côncavo com declives mais fortes, sendo comum a presença de dales na forma de anfiteatros de erosão em cabeceiras de drenagem. A figura 2 mostra o aspecto do relevo observado nessa classe. 


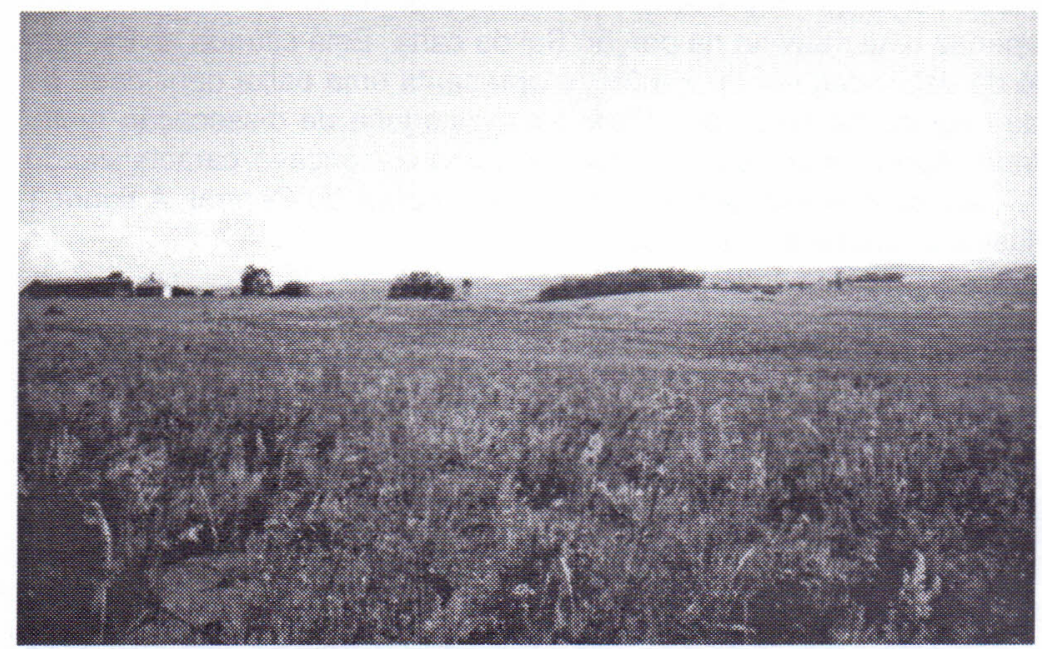

Fig. 2. Aspecto da área com Dissecação Fraca do relevo. Localidade de Parada Link, município de São Pedro do Sul-RS

Fonte: Pesquisa de campo- Fevereiro - 2000

A classe de Dissecação Média, que ocupa aproximadamente 18.000 ha, representando $26,75 \%$ do total da área, aparece em porções que estão distribuídas por toda a folha topográfica, em regiões com declividades mais acentuadas, tanto no setor da Depressão Central como no Rebordo do Planalto.

As áreas com dissecação média, apresentam relevo ondulado, como mostra a figura 3. São encontradas regiões de grande fragilidade e passíveis de sofrerem processos de erosão acelarada. Este fenômeno é observado frequentemente nesta categoria de dissecação. Nesta classe de dissecação, a natureza das formações superficiais e processos morfodinâmicos presentes na maioria das vezes, constituem fatores limitantes às atividades agrícolas. A figura 6, apresenta o aspecto da classe obtida como de dissecação média.

As áreas ocupadas pela classe de Dissecação Forte representam $17,53 \%$ do total da área correspondendo a 11.800 ha. Estas áreas estão situadas na área do Rebordo do Planalto caracterizam-se por apresentar declividades acentuadas. Frequentemente essas vertentes apresentam erosão acelerada. Principalmente nas áreas com agricultura e pastagem, o que demonstra grande limitação imposta pela forte dissecação do relevo. A figura 4 dá o aspecto predominante do relevo dessa classe de dissecação. 


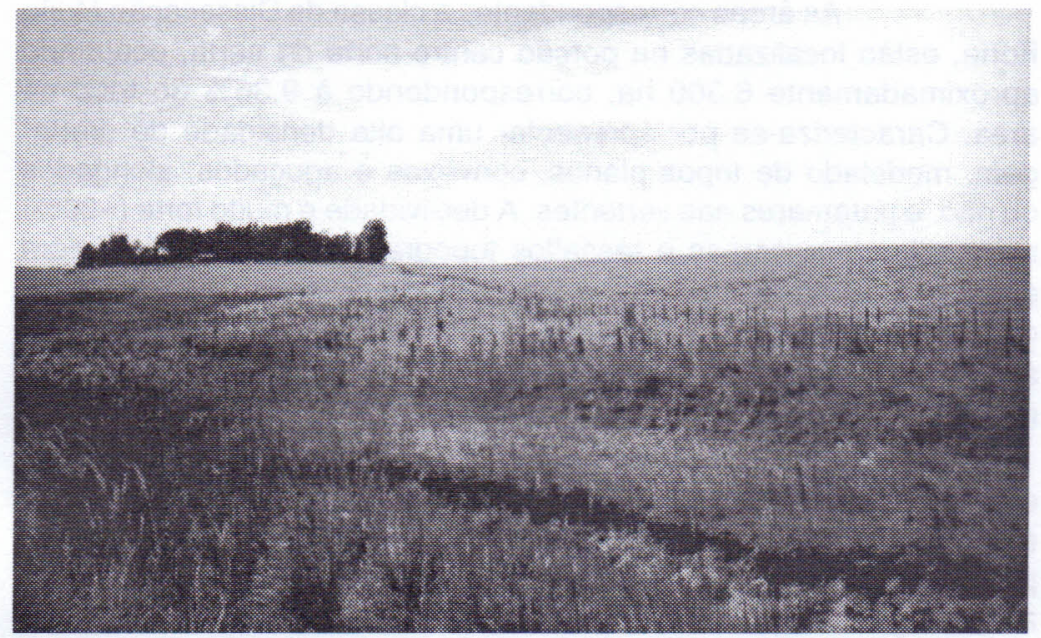

Fig. 3. Modelado convexo-côncavo com inclinação forte caracterizando a classe de Dissecação Média do relevo. Localidade de Inhamandá, município de São Pedro do Sul-RS

Fonte: Pesquisa de campo- Fevereiro - 2000

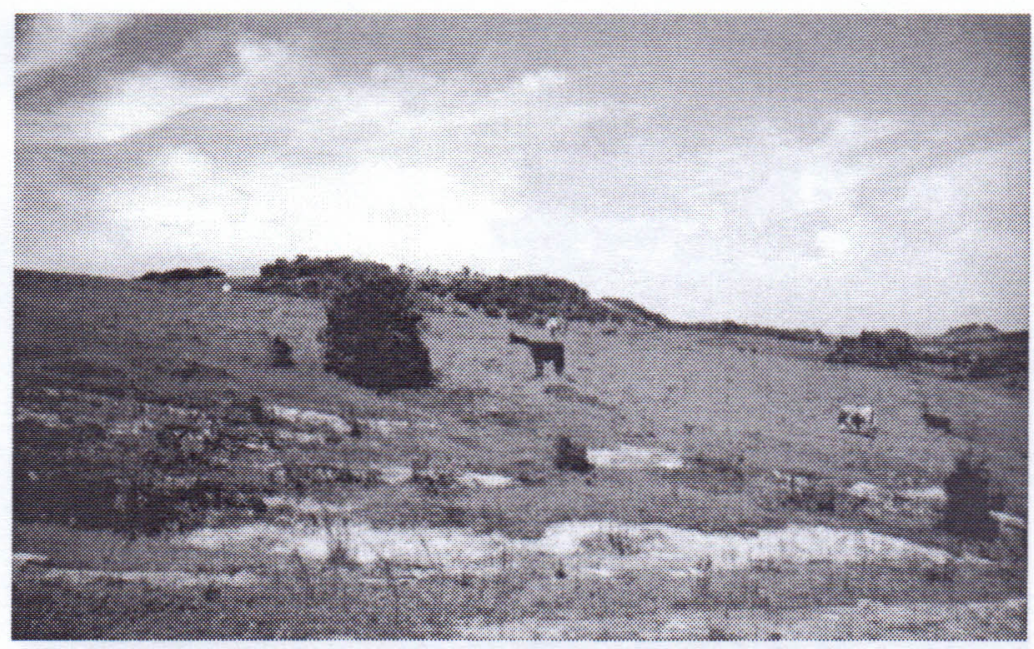

Fig. 4. Aspecto da classe de Dissecação Forte do relevo. Localidade de Cerro do Prass, município de São Pedro do Sul-RS

Fonte: Pesquisa de campo- Fevereiro - 2000 
As áreas correspondentes a classe de Dissecação Muito Forte, estão localizadas na porção centro-norte da carta, ocupando aproximadamente 6.300 ha, correspondendo à $9,36 \%$ do total da área. Caracteriza-se por apresentar uma alta densidade de drenagem, modelado de topos planos, convexos e aguçados, alongados ou não, e patamares nas vertentes. A declividade é muito forte ( $>30 \%$ ) apresentando escarpas e ressaltos topográficos. Apresenta-se com elevado grau de declividade, é uma área pedregosa, situada na região do Rebordo do Planalto, área típica de encostas íngremes com alta capacidade de transporte de sedimentos morro abaixo, ocasionando a formação de canais fluviais efêmeros.

São áreas onde o relevo e os processos morfodinâmicos constituem fatores limitantes para o desenvolvimento de práticas agropecuárias. Constituem as áreas que devem ser destinadas a preservação permanente, podendo serem exploradas pela sua beleza cênica.

As atividades agropecuárias podem ser desenvolvidas com técnicas conservacionistas adequadas, nos patamares que são comuns nas áreas de encostas. Já nas planícies fluviais a atividade agropecuária pode ser desenvolvida plenamente. A figura 5 mostra as feições predominantes nessa classe.

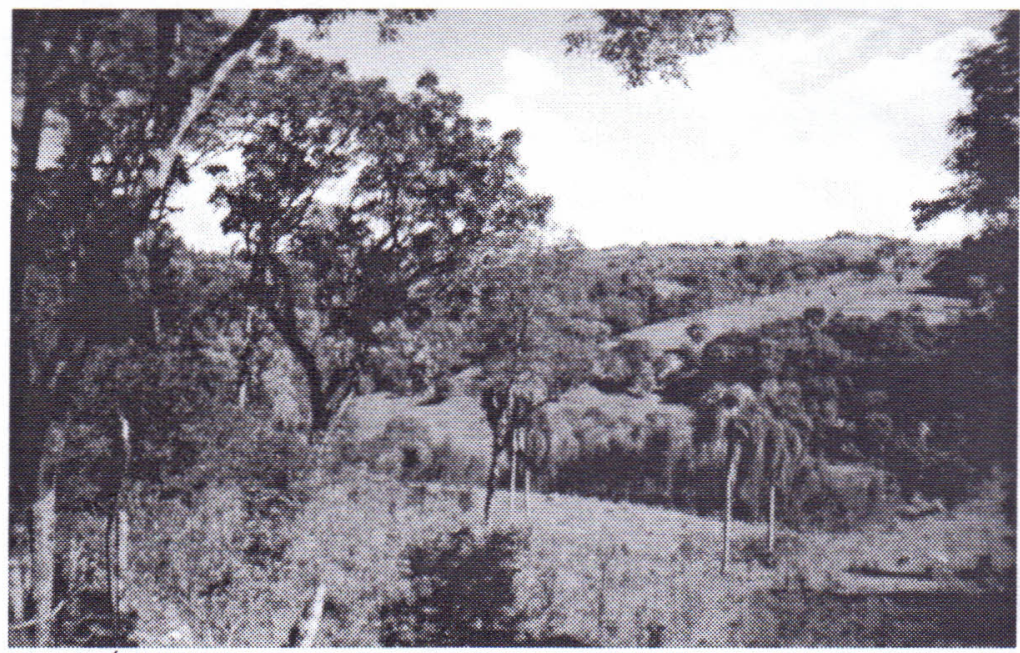

Fig. 5. Área de Dissecação Muito Forte do relevo, nas proximidades do Arroio Guassupi. Localidade de Guassupi, município de São Pedro do Sul-RS

Fonte: Pesquisa de campo- Fevereiro - 2000 
As áreas de Acumulação ocupam aproximadamente 7.580 ha, o que representa $11,26 \%$ da área total. Englobam as formas originadas por processos de coluviação e de deposição fluvial, onde se encontram sedimentos detríticos não consolidados. As áreas de acumulação estão localizadas nas várzeas dos rios IbicuíMirim e Toropi. Como pode ser visualizado na figura 6, as áreas de acumulação encontradas na área da carta de São Pedro do Sul, são ocupadas preferencialmente com o cultivo do arroz e usada como área de pastoreio na entresafra. São áreas periodicamente inundadas com a retirada da cobertura vegetal nas cabeceiras e margens do rios, a ocorrência de desbarrancamentos, destruição dos diques marginais e assoreamento dos rios, vem sofrendo um aceleramento o que provoca um aumento da amplitude e frequência das inundações.

Na planícies fluviais, presentes na folha topográfica de São Pedro do Sul, são encontradas jazidas de areia e argila para a construção civil. A figura 6 mostra o aspecto dessas áreas.

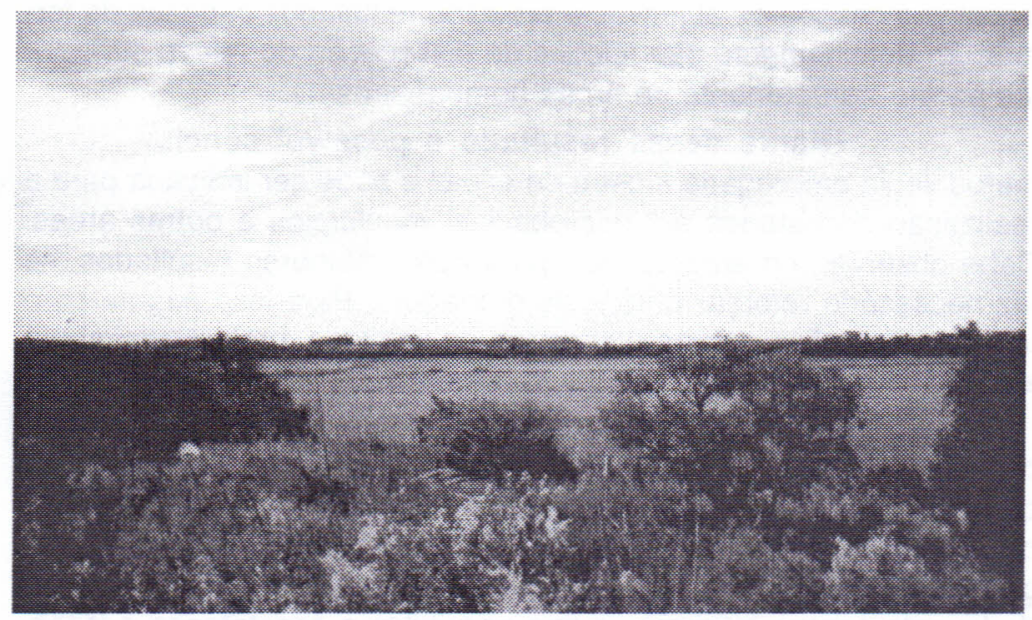

Fig. 6. Acumulação de Planície Fluvial nas margens do rio Ibicuí-Mirim. Localidade de Catanduva, município de São Pedro do Sul-RS Fonte: Pesquisa de campo- Fevereiro - 2000

As áreas de Aplanamento encontradas e mapeadas, ocupam 563 ha, representando $0,85 \%$ da área total. Caracterizamse pelo modelado aplanado, levemente ondulado e ressaltos topográficos na borda dos divisores de água. Apresentando-se sob a for- 
ma de morros testemunhos, individualizando-se de maneira saliente dentro da paisagem local, por representarem as maiores elevações do relevo, no caso dos morros residuais, e ressaltos topográficos entre os divisores das microbacias hidrográficas.

São áreas que para serem utilizadas com culturas agrícolas, devem ser propostas técnicas conservacionistas adequadas, para amenizar os efeitos dos processos erosivos em decorrência das características morfodinâmicas e da textura das formações superficiais, que freqüentemente são cascalhentas.

A distribuição espacial dos modelados de dissecação, aplanamento e acumulação podem ser visualizados na figura 7 .

\section{CONSIDERAÇÕES FINAIS}

Considerando o objetivo da pesquisa, que foi a elaboração da carta de dissecação do relevo para a folha topográfica de São Pedro do Sul, em uma escala grande (1:50 000) entende-se que o trabalho alcançou os objetivos e produziu resultados capazes de formar um detalhamento das feições de dissecação do relevo suficientes para o agrupamento de áreas homogêneas.

Diante desse resultado é possível concluir que a metodologia empregada mostra-se eficaz e pode ser indicada para a realização de estudos em microbacias, municípios e outras áreas. Cabe observar, no entanto, que para obter melhores resultados, se faz necessário reforçar a rede de drenagem. Para isso sugere-se o uso de fotografias aéreas e imagens de satélites, preferencialmente em escala maior do que a base cartográfica utilizada.

Quanto a aplicação da metodologia, as principais dificuldades encontradas foram a identificação e a definição das áreas de acumulação e aplanamento, aliada a dificuldade em estabelecer onde cessam os processos de dissecação e iniciam os de acumulação. Para facilitar este reconhecimento, recomenda-se a realização de levantamentos à campo, o que possibilita a constatação e localização destas áreas.

Para a realização de planejamentos integrados, recomenda-se que outros estudos sejam elaborados, visando o conhecimento das potencialidades e restrições de uso oferecidos por esta área.

É importante destacar que os resultados aqui apresentados são válidos para as condições, características dos materiais usados e área estudada. Por outro lado, a metodologia usada na 112 Ciência \& Natura, Santa Maria, 24: 101 - 116, 2002. 
elaboração deste trabalho pode ser aplicada para o estudo da dissecação do relevo de outras áreas, devendo-se realizar o ajuste dos dados da matriz dos índices de dissecação para a escala do trabaIho.

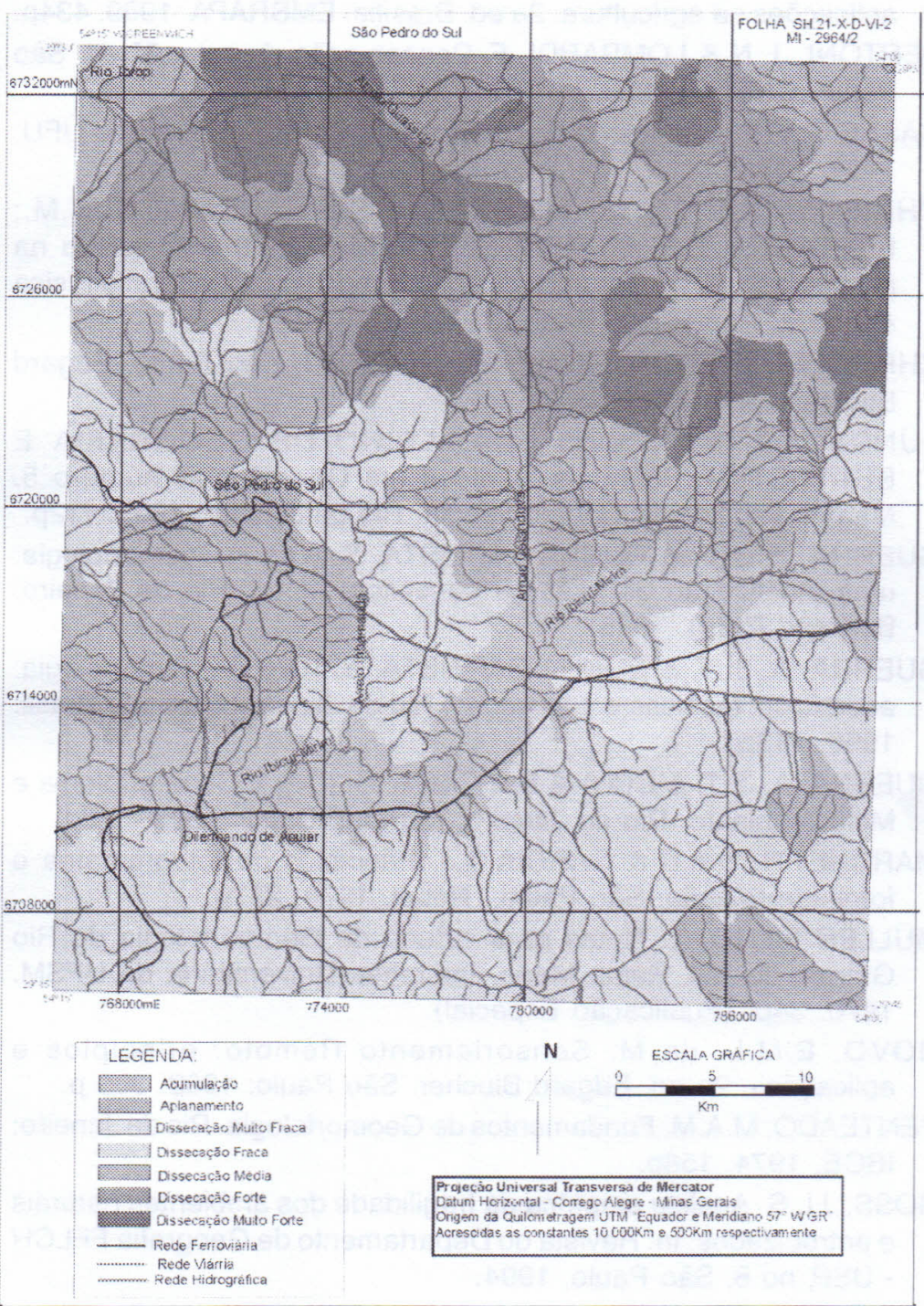

Fig. 7. Distribuição dos modelados de relevo da carta topográfica de São Pedro do Sul-RS 


\section{REFERÊNCIAS BIBLIOGRÁFICAS}

ASSAD, E.D. \& SANO, E.E. Sistema de Informações Geográficas: aplicações na agricultura. 2a ed. Brasília: EMBRAPA. 1999. 434p. BERTONI, J. N \& LOMBARDI, F. Conservação do solo. $3^{a}$ ed. São Paulo: CERES, 1983.

CASSETI, V. Elementos de Geomorfologia. Goiânia: Editora da UFU, 1994. 137p.

CHRISTOFOLETTI, A.; TELES, A. P.S.S.; LUPINACCI,C.M.; BERTAGNA, S.M.A.; MENDES, I.A. Morfometria do relevo na média bacia do rio Corumbataí. In: V Simpósio de Geografia Física Aplicada. Anais. São Paulo, 1993. (137-139).

CHRISTOFOLETTI, A. Geomorfologia. 2a ed. São Paulo: Edgard Blucher, 1980. 188p.

FUNDAÇÃO INSTITUTO BRASILEIRO DE GEOGRAFIA E ESTATISTICA. Manuais técnicos em Geociências número 5. Manual Técnico de Geomorfologia. Rio de Janeiro: 1995. 112p.

GUERRA, A. J. T. \& CUNHA BAPTISTA, S. (Org.). Geomorfologia: uma atualização de bases e conceitos. $2^{a}$ ed. Rio de Janeiro: Bertrand Brasil. 1995.

GUERRA, A. J. T. \& CUNHA BAPTISTA, S. (Org.). Geomorfologia: exercícios, técnicas e aplicações. Rio de Janeiro: Bertrand Brasil. 1996. 343p.

GUERRA, A. J. T. \& CUNHA BAPTISTA, S. (Org.). Geomorfologia e Meio Ambiente. Rio de Janeiro: Bertrand Brasil. 1996. 372p.

MARCHETTI, D.A.B \& GARCIA,G.J. Princípios de fotogrametria e fotointerpretação. São Paulo:. Nobel. 1978. 257p.

MÜLLER FILHO,I.L. Notas para estudo de Geomorfologia do Rio Grande do Sul. Santa Maria, Imprensa Universitária da UFSM, 1970. 34p. (Publicação Especial).

NOVO, E.M.L. de M. Sensoriamento Remoto: princípios e aplicações. 2a ed. Edgard Blucher. São Paulo: 1992. 308 p.

PENTEADO, M.A.M. Fundamentos de Geomorfologia. Rio de Janeiro: IBGE, 1974. 158p.

ROSS, J.L.S. Análise empírica da fragilidade dos ambientes naturais e antropizados. In: Revista do Departamento de Geografia FFLCH - USP, no 8, São Paulo, 1994.

ROSS, J.L.S. Geomorfologia Aplicada aos Eias-Rimas. In: GUERRA, A. J. T. \& CUNHA BAPTISTA, S. (Org.). Geomorfologia e Meio 
Ambiente. Rio de Janeiro: Bertrand Brasil. 1996. 372p. (p.291-336). ROSS, J.L.S. As Superfícies de aplanamento e os níveis Morfológicos na Bacia do Alto Paraguai -Cuiabá. In: IV Simpósio de Geografia Física Aplicada. 1991, Porto Alegre. Anais. Porto Alegre: Instituto de Geociências, 1991. p. 84-93.

SANCHEZ, M.C.; GARCIA,J.R.Y.; SOUZA,A.P.; MENDES,I.A. Sugestões para elaboração de cartas morfométricas em áreas costeiras e cristalinas. In: V Simpósio de Geografia Física Aplicada. Anais. (307-310). São Paulo, 1993.

VIEIRA, L. S. \& VIEIRA, M. de Nazareth Figueiredo. Manual de Morfologia e Classificação de Solo. $2^{a}$ ed. São Paulo: CERES, 1983.

VIEIRA,L.S.; SANTOS,P.C.T.dos \&VIEIRA, M. de N.F. Solos: propriedades, classificação e manejo. Brasília: MEC/ABEAS, 1988.154p. (Programa Agricultura nos Trópicos, V.2). 


\section{Jair Antônio Raffaelli Mauro Kumpfer Werlang LEA - Laboratório de Estudos Ambientais Departamento de Geociências - CCNE Universidade Federal de Santa Maria Santa Maria, RS - Brasil}

